\begin{abstract}
Concern about partisan audiences blindly following partisan news brands while simultaneously being unable to distinguish the credible news from hoax news dominates media criticism and theoretical inquiries. Companies and media literacy advocates have suggested credibility labels as a solution. This experiment tests the effectiveness of credibility labels at the intersection of partisan news brands and partisan news stories. Using news credibility theory and Partisan Media Opinion hypothesis, it investigates the effects credibility labels have on partisan audiences, partisan news brands, and partisan news stories. It finds credibility labels may be an effective news literacy tool, and that credibility is enhanced when the news story's ideological perspective does not match the ideology of the news brand.

Keywords: partisan news, media literacy, cheap and costly talk, news credibility, experiment
\end{abstract}




\section{WHAT’S IN A LABEL? NEGATIVE CREDIBILITY LABELS IN PARTISAN NEWS}

Ideological news outlets are more common as online platforms have reduced the cost of publishing and increased the geographical reach of information (Iyengar \& Hahn, 2009). These news brands cater to audiences who expect them to deliver information that agrees with their ideological worldview (Stroud, 2008). In some cases, brands catering to both liberals and conservatives were owned by the same company (Silverman, Lytvyneko, Vo, \& Singer-Vine, 2017), suggesting these companies were built to profit rather than to serve the public reliable information. The proliferation of unreliable information, hoaxes and ideological "click-bait" garnered so much attention, technology companies were pressured into exploring solutions to stop the spread of inaccurate information.

The founder of a company that aims to label news brands based on their credibility, NewsGuard, estimates that Americans today are audience to about 7,500 news brands (Farhi, 2018). While many mainstream brands such as ABC, CBS, NBC, NPR, PBS and CNN are trusted by at least half of Americans that have heard of them (Jurkowitz, Mitchell, Shearer, \& Walker, 2020), more than 180 partisan news websites were started in 2016 alone that most have never heard of before (Silverman, Lytvyneko, Vo, \& Singer-Vine, 2017). The reputations of familiar brands provide cues to the credibility of the information in the news. When the audience lands on the page of one of these unknown news brands, though, they cannot know the reputation of the source and therefore cannot rely on this important cue to judge the credibility of many of these news brands. This fractured news brand ecology, rife with brands that cater to an ideological audience creates a culture where news brands receive a credibility boost or penalty among partisans based on the brand's position along the ideological spectrum. 
Companies like Google and Facebook took steps in 2016 to reduce the effect of partisan hoax news on their platforms by introducing credibility labels. Google added fact-checking labels to search results to respond to criticism that the search engine was a willing player in spreading false news (Bergen, 2017). Facebook for a time added a label system that warned of "fake news," though the company has since dropped the system. Then, Steven Brill grabbed announced his initiative to develop a "nutrition label for news" (Farhi, 2018). Brill and his partners believed that labeling each news outlet can stop the problem of non-credible news outlets spreading false news (Farhi, 2018). Researchers have called for more implementation of algorithmic credibility systems (Lewandowsky, Ecker, \& Cook, 2017).

The credibility label is one response to improve news media literacy by giving audiences an expert heuristic cue to help overcome the audiences' ideological confirmation bias. While past research shows partisans prefer to read likeminded news and judge it to be more credible (Garrett, 2009; Westerwick, Johnson, \& Knobloch-Westerwick, 2017), little research has been done on how a credibility label could alter that tendency. The Heuristic Systematic Model (HSM; Chaiken, 1980) provides a framework to understand that audiences make credibility judgements based on the cues available to them. Some of the common cues that influence partisans include the news brand and political party identifiers. The Partisan Media Opinion hypothesis (Baum \& Groeling, 2009a) suggests that when those cues are in conflict, audience perceptions of credibility could increase. Could the addition of a credibility label change that perception and provide a new tool for media literacy?

The purpose of this study is to pit three different cues to a credibility decision against each other in an online news environment. Will audiences choose to pay the most attention to a credibility label, a partisan-aligned news brand, or the content of a news story that agrees with 
their worldview? Or, will it be an interaction of the cues? To test these three elements, this study manipulates the partisan nature of a news story and a news brand. Additionally, it introduces a negative credibility label. It tries to understand for whom and on what news stories and news brands a negative news label would be effective as audiences struggle with competing types of heuristic cues to credibility. With these goals in mind, the study addresses how audience perceptions of credibility can be decreased by introducing a label that indicates a news story has negative credibility in a variety of ideological contexts.

\section{Literature review}

News credibility has been quantitatively studied since the 1940s (McCroskey \& Young, 1981). When news moved online, credibility research saw a sharp uptick (Flanagin \& Metzger, 2000). In the most recent decade, amid concerns about partisan bubbles and misinformation, journalism scholars are turning to research on how to guide audiences to a "correct" credibility judgement. Credibility, an abstract concept, is generally understood to be an attribute that helps shape the message receiver's perception of the message (Gunther, 1988). Credibility is the believability of information that created by its perceived expertise and trustworthiness (Metzger, Hartsell, \& Flanagin, 2015; Newell \& Goldsmith, 2001) and a result of "a cognitive process by which information is filtered and selected" (p. 1031, Liu, 2004). Though definitions of credibility are rarely made explicit in communication research (Kohring \& Matthes, 2007), researchers often define credibility by measurements of the perception of credibility when analyzing individual news messages, journalists, news brands or mediums. The level of analysis of credibility can be zoomed in to a specific message or pulled back to look at its modality, but in online news the credibility of the source, medium and message are difficult to separate (Sundar, 
2008). Researchers measure credibility at the different units of analysis using the same scale (Kiousis, 2006).

Because credibility is a perception, understanding how audiences develop those perceptions is important for understanding what audiences believe. Much research focuses on what parts of a message and message source most strongly influences the perception. This research finds audiences pay attention to specific heuristics such as the reputation of the news brand or the gender of the journalist delivering the news (Armstrong \& McAdams, 2009; Metzger, Hartsell, \& Flanagin, 2015). A system where audiences could rely on simple cues like the name of the publication helped audiences who did not have the access, knowledge or time to investigate each story for its veracity. The Heuristic Systematic Model of information processing (Chaiken, 1980) was integrated into news research (Metzger, Flanagin, Eyal, Lemus, \& McCann, 2003; Metzger, Hartsell, \& Flanagin, 2015) to explain how audiences quickly and efficiently determine credibility. This processing model says that audiences will default to heuristic cues (Chaiken \& Maheswaren, 1994), or easily digested hints at the credibility of a news story unless otherwise motivated. For much of the $20^{\text {th }}$ Century, the heuristics audiences relied on to judge the credibility of news remained unchanged. Because of this audiences could be told to look for a checklist of visible credibility cues, such as news brand reputation (Sundar, 2008), or format of the news (Burbules, 1998). Online new added other technology affordances, such as navigability and interactivity that also influenced the perception of information mediated by computers (Sundar, 2008).

The emerging online ecosystem of unfamiliar news brands and constantly changing design has disrupted that set of heuristic cues, making it more difficult to make credibility decisions with little cognitive effort (Bucy, 2004; Sundar, 2008). The most basic heuristic cue, 
the news brand reputation, is less reliable now because of the dozens of news brands available to the audience, some of which are malicious (Marsh \& Yang, 2017). Online news introduced heuristic non-content cues like update times, social recommendations (Xu, 2013), bandwagon effects (Go, Jung \& Wu, 2014), and aggregated news rankings by algorithms (Sundar, KnoblochWesterwick, \& Hastall, 2007) that influence the perception of credibility. The ability of the audience to interpret cues and navigate these new layouts is limited (Bucy, 2004).

\section{Partisan news brands}

When audiences face a complex system of conflicting cues to credibility, they will tend to act as cognitive misers (Fiske \& Taylor, 1991). One of the quickest cues to credibility is the news brand's reputation for credibility. In the case of ideological news brands, this cue is so strong that partisans make different credibility judgments about the same content depending on the relationship between the ideologies of the news brand and the audience member (Coe, Tewsbury, Bond, et al, 2008). When news brands carry an ideological association, audiences use this heuristic cue as a guide to the credibility of the storyteller that overpowers the credibility of the content (Ariyanto, Hornsey, \& Gallois, 2007; Baum \& Gussin, 2008).

Though uses and gratification theory suggests myriad of reasons that an audience member makes a particular news selection (Katz, Blumler, \& Gurevitch, 1974), research suggests audiences tend to choose news they perceive as credible (Metzger, Hartsell, \& Flanagin, 2015; Tsfati \& Cappella, 2003). In a news media landscape where audiences choose their view of truth based on the ideological heuristics of the news publisher, the public can become more ideologically polarized (Baum \& Groeling, 2008; Stroud, 2010).

Evidence of this has emerged in studies of cable news. Audiences who viewed the same news clip reported differing levels of bias when the clip was attributed to either Fox News 
Channel or CNN (Turner, 2007). While cable news broke from traditional broadcast news by embracing ideological branding (Coe, Tewksbury, Bond, et al, 2008), online news has only further diversified, polarized and expanded the availability of news on partisan brands. Some news brands are carving out niches of politically polarized audiences (Stroud, 2008; Stroud \& Lee, 2013). Audiences can choose news media outlets that are ideologically consistent with their own beliefs (Iyengar \& Hahn, 2009; Stroud, 2008), and can argue away news that is ideologically inconsistent (Taber \& Lodge, 2006).

The existing literature on the role of ideological news brands relies on the immediately recognizable names of existing cable stations with established reputations. However, with 180 new partisan news brands emerging in only a single year, it is increasingly likely that audiences will encounter unfamiliar and unknown news brands. Silverman, Lytvyneko, Vo and SingerVine (2017) demonstrated these news brands were putting not-so-subtle cues to their partisanship in the name, such as "Conservative 101 " or "Liberal Society." These sites carry less authority to persuade audiences than established and studied cable news. Yet, news brands with these names carry clear heuristic cues that audiences who want to rely on authority could believe when facing a decision, and which Silverman, Lytvyneko, Vo, and Singer-Vine (2017) show garnered considerable engagement from partisans.

\section{Partisan news message}

When partisans engage with news that is incongruent with their worldview, they are prone to counter-arguing and dismissing that information (Taber \& Lodge, 2006). Confirmation bias is another result of the audience's goal to spend as little cognitive effort on processing information as possible. People seek out information that confirms rather than challenges their worldview (Festinger, 1957) In a news context, this means audiences will where possible 
selectively choose to the information that supports their partisan ideology because it requires the least updating on their part (Stroud, 2008).

Specifically, audiences appear to be motivated to seek out news messages with which they will politically agree (Garrett, 2009) and to avoid messages with which they will politically disagree (Garrett, Carnahan, \& Lynch, 2013). This results in a phenomenon known as selective exposure, which suggests audiences will spend less time with messages with which they disagree than agree (Sears \& Freedman, 1967; Westerwick, Johnson, \& Knobloch-Westerwick, 2017). In a context where audiences are encountering an ideological news brand for the first time, they may be particularly vulnerable to cognitive bias. Where audiences know the reputation of familiar news brands, they can trust the content to be politically aligned. When, though, that history and reputation are absent, audiences may question the ideological honesty professed in a news label and instead choose content which provides the path of least cognitive effort to decide whether to believe the information.

\section{Interaction between partisan messages and partisan sources}

Understanding how audiences might process news that comes with both an ideological news brand and an ideological news message complicates the information processing models. Will the authority of an ideological news brand be trounced by the tendency to continue believing a set of facts explained by cognitive bias? Borrowing a theory from political science to think about partisan news brands as political actors can shed light the three-way interaction between the news audience, news brand and news story.

Partisan Media Opinion (PMO; Baum \& Groeling, 2009a) claims audiences will perceive intra-party criticism as more credible than cross-party criticism. Conversely, audiences will perceive cross-party praise as more credible than intra-party praise (p. 31). The match between 
the perceived political ideology or perceived party alliance of the news brand and the valence toward the ideology of the content results in two categories of "talk." Cheap talk is the expected type of rhetoric: Praise of the same party or criticism of the opposing party. Costly talk is the unexpected type of rhetoric: Criticism of the same party or praise of the opposing party.

Audiences appear to perk up and be more cognitively engaged when they view costly talk. Audiences reported larger credibility effects when politicians presented ideas seemingly countering the presumed ideology of the news brand than when the politicians' claims were in lock-step with the news brand ideology (Baum \& Groeling, 2009b). Mismatches between the audiences' partisanship and the perceived ideology of a news brand are more prone to counterarguing, which decreases the perceived credibility when audiences dismiss a message because it comes from a news brand from "the other side." However, mismatches between the ideology of a politician and the news brand can increase credibility. Costly talk improves perceptions of credibility because it means the message sender is going against its perceived selfinterests. While cheap talk is more likely to trigger counterargument, so that audiences were less likely to update their opinion (Baum \& Groeling, 2009b), costly talk boosts credibility. Additionally, the credibility boost of costly talk is larger when the audience member identifies with the same party as the politician than when the politician is from the opposing party.

It is important to note that Baum and Groeling (2009a, 2009b) measured the effects of costly and cheap talk on the evaluations of the politician in the news. The authors, centrally focused on the effect of rhetoric of politicians on public opinion regarding foreign policy and war, did not measure the effects of costly and cheap talk on evaluations of the news brand nor the content. Nevertheless, if news brands and the content it chooses to publish are seen as 
political actors, the Partisan Media Opinion hypothesis could be extended from politicians to news credibility to help explain how audiences will process the heuristic cues of the news.

H1: News that is ideologically inconsistent between news brand and news content (costly talk) will be perceived as more credible than news that is ideologically consistent (cheap talk).

Though not explicitly looking for it, Coe, Tewksbury, Bond, et. al (2008) found an interaction between political content and cable news brand on the perception of bias. In an experiment that showed actual news clips from CNN, Fox News Channel, and "The Daily Show," they found a relative hostile media effect so that participants rated news programs as more biased when they perceived the program to be ideologically opposed to their beliefs. Further, they found that the content of the news story shown in the particular clip interacted with the news brand. Here they found a news story about war in Iraq was perceived as more biased on Fox among liberals than war news on $\mathrm{CNN}$ by conservatives. Taken together, these experiments and surveys suggest partisan cues in news brand names or news content both play a central role in the perception of credibility by the audience. This suggests that there may be interactions between the partisan cues of the news brand and the partisan cues in the content of the news.

H2: In absence of news credibility label, cheap/costly talk will interact with the audience's ideology so that costly talk from a likeminded news brand will be perceived as more credible than cheap talk from an oppositional news brand.

\section{Credibility labels and algorithms}

In the modern news environment, as corporate actors and media literacy advocates try to solve the "fake news" crisis, a fourth variable enters the picture of perceived credibility of news: credibility labels (Sundar, 2008). Credibility labels seem like a natural evolution of the burgeoning industry of fact-checking journalism. Fact-checking journalism set out to analyze the 
claims of politicians and cut through the tendencies of partisan cognitive bias of the audience (Graves, 2016). In fact-check journalism, the audience is asked to pay attention to either the authoritative cues of the fact-check or the ideological cue of the politician making the original claim (Young, Jamieson, Poulsen, \& Goldring, 2017). Heuristically processed symbols that definitively tell the audiences the truth of a partisan claim work better to overcome the audience's cognitive bias than more systematically processed contextual corrections (Amazeen, Thorson, Muddiman, \& Graves, 2018). Perhaps inspired by the success of fact-checking journalism, 2018 ushered in a "gold rush" in the online news credibility labeling cottage industry (Oremus, 2019).

Though there are many similarities between the symbol-based fact-check and the symbolbased credibility label, there are some distinctions that may cause audiences to react differently. First, while fact-checks are about a specific claim made by a public figure that was already publicized (Graves \& Glaisyer, 2012), a credibility label is applied to an entire news story that an audience member is reading often for the first time. Second, fact-checks are done by human journalist (Graves \& Glaisyer, 2012) and credibility labels are more often done by an algorithm and applied to a news story in its entirety or news brand to which the audience has no prior exposure.

The role of journalism algorithms has grown as journalists try to create at the scale and scope of the internet (Diakopoulos, 2019). Facebook, for example, abandoned placing a label on misinformation because the task done by a human could not respond at the speed and scale of the online environment (Silverman, 2017). Additionally, some were concerned because of the backfire effect research (Nyhan \& Reifler, 2010) and because a study suggesting the articles near a disputed article would get a credibility boost (Pennycook \& Rand, 2017). 
In addition to the speed and scale that algorithms provide, machines are seen by the audience as less biased and more credible than journalists (Waddell, 2019). When audiences are told that a news article is written by an algorithm, they give it higher scores regardless if it was actually written by a machine or a human (Jung, Hong, Kim, Im, \& Oh, 2017). Even when audiences trust the human journalists at a news organization, a machine byline increases the story's perceived credibility and objectivity (Liu \& Wei, 2019). While these studies are about news stories rather than news labels, the perception that machines are an authoritative source and less biased than humans appear pervasive (Jung, Hong, Kim, Im, \& Oh, 2017; Liu \& Wei, 2019; Waddell, 2019). This suggests that if the audience is told that a credibility label is calculated by an algorithm, audiences will consider that an authoritative cue to the news story's credibility.

\section{Concern about a backfire effect}

For other evidence suggesting the effectiveness of labels comes from fact-checking journalism, which similarly tries to get audiences to overcome cognitive bias by engaging with an authoritative cue by analyzing a claim of a politician for its truthfulness. Early results suggested that the authority of the local news station wins when pitted against the ideological cue of the partisan politician (Ansolabehere \& Iyengar, 1996; Cappella \& Jamieson, 1994; O’Sullivan \& Geiger, 1995).

After the turn of the century, fact-checking literature changed course when several studies found backfire effects when partisans were exposed to corrective (Nyhan \& Reifler, 2010; Prasad, Perrin, Bezila, et al, 2009; Schaffner \& Roche, 2016). The fear that corrective information might do more harm than good is largely rooted in a Nyhan and Reifler (2010) finding that partisans defensively process information corrections that run counter to their preexisting beliefs so that they actually strengthen their beliefs instead of accepting the corrective 
information as true. In two studies, the authors found corrective information led to more extreme opinions among those who were predisposed to believe the original claim because it aligned with their ideological beliefs. Moderates and those who held opposing ideological beliefs did not demonstrate this backfire behavior to corrective information. Even when a correction effectively changes the belief about a partisan fact, the original misconception may still play a part in the decisions and perceptions of partisans in what Thorson (2015) dubbed "belief echoes." These studies suggest those who are most likely to believe a misconception appear to double-down on those beliefs when told they should abandon them.

However, several attempts to replicate a backfire effect have failed (Porter \& Wood, 2019; Wood \& Porter, 2018), and researchers suggest that the observed effects may not reflect actual changes in belief but rather the desire for audiences to perform their partisanship to others (Bullock, Gerber, Hill, \& Huber, 2015). This more recent literature finds evidence that audiences generally accept the authoritative cue over the ideological cue and update their beliefs about facts in the corresponding direction of the fact check (Bullock, Gerber, Hill \& Huber, 2015; Porter \& Wood, 2019; Wood \& Porter, 2018). Though that is encouraging, audiences tend to update their opinions to a degree relative to their original position (Porter \& Wood, 2019; Wood \& Porter, 2018). This means that some ideological groups decreased their beliefs in misinformation than others, suggesting relying on a combination of both the authority of the fact check and prior beliefs to come to an ultimate decision about what to believe.

H3: The perception of credibility will decrease when a negative credibility is applied to the story. 
H4: Those who share ideological identity consistency with a partisan news brand will decrease their perception of credibility less after the introduction of a negative credibility label than partisans who are ideologically inconsistent with the news brand.

RQ1: How will a news credibility label interact with the relationship between the audience and the news brand?

RQ2: How will a news credibility label interact with the relationship between the news brand and the content of the news story to affect the perception of credibility?

\section{Method}

To test these hypotheses and the research question, I designed a multi-step 3 (ideology consistency between the audience and the news brand) X 2 (costly/cheap talk relationship between the news brand and the news content) survey-embedded online experiment.

\section{Participants}

Participants for this experiment were recruited through Survey Sampling International. Four hundred participants reached the completion screen of the experiment. Ten participants were removed from analysis because they took less than five minutes to complete the experiment and left many answers blank. Participants averaged 21 minutes to complete the experiment ( $M=1,267$ seconds, $S D=950$ seconds).

Participants were on average aged 48 when they participated in the experiment. The gender was evenly split (49.7\% male, $49.7 \%$ female). Most were white (83 percent), with minority representation slightly lower than the population of the United States $(8 \%$ Black, $6 \%$ Asian; $8 \%$ Hispanic). ${ }^{1}$ Most participants had at least a college degree (51\%), which is more than

\footnotetext{
${ }^{1}$ Percentages sum to more than 100 because participants were able to select multiple racial and ethnic
} identifiers. 
the national average (U.S. Census Bureau). In this survey, I measured partisanship and ideology on separate scales. Both were fairly even, with a slight plurality to Democrats and moderates. Partisanship: 37.5\% Democratic, 36\% independent, and 26.5\% Republican. Ideology: 32.6\% liberal, $37.7 \%$ moderate, and $29.7 \%$ conservative. Participants were paid incentives for participating by the survey administrator company.

The number of participants needed for this survey design was estimated using a power analysis based on an alpha of .05 , an effect size of 0.5 and a power of 0.8 . This calls for 64 participants per cell. With a six-cell design, the estimated number of participants needed is 384 . To account for bad data or drop outs, 400 participants were recruited. The responses of 390 were analyzed, giving this data a power of .81 for a two-tailed t-test.

\section{Design}

This experiment was embedded in an online survey and measured credibility at different points. This design allows me to track the changes in the perception of credibility within-subject while also comparing the between-subject effects of cheap talk and news brand ideology manipulations. While it loses some of the explanatory power a full-factorial design could have on finding some effects in isolation of previous exposures, it allows me to investigate who changes their perception of credibility. This advantage is important to answering the question of what interventions news media outlets can do to promote truthful news over hoax news. This means that analysis was done between subjects in a 3 (ideological consistency between the news brand and the audience) X 2 (relationship between the news brand and the content) design as well as a 2-cell within-subjects experiment (before and after instructions on how to interpret the heuristic credibility cues). 
Participants were exposed to three pieces of stimulus material that were designed to mimic a news application for desktop and mobile devices. This medium was chosen because the layouts of news apps are not standardized to the extent that audience members expect certain heuristic credibility cues. It is in this environment that the presence of unfamiliar heuristic cues would not be jarring, or that instructions on how interpret the heuristic credibility cues would be unusual. The first piece of stimulus material was a non-political story detailing a scientific controversy about the future maximum human height. The second piece was a political story detailing a not-yet-released documentary about the justice system that partisans criticized for being biased. The third piece of stimulus material was the same news story about the controversial documentary with the addition of instructions on how to interpret the credibility label, and notations about the meaning of the heuristic credibility cues that indicated the news story received a negative credibility rating by an algorithm.

Like all controlled experiments, this design tries to balance ecological realism with internal validity. To that end, the design of the general news app design drew elements from emerging news apps available in the iTunes store, including large news brand names, text on a white background, and a headline above a short story.

To invoke an ideological news brand, the identifiers "Liberal" or "Conservative" were used in the news brand names and paired with the appropriate political animal symbol (donkey or elephant). To invoke partisan cues in the political news stories, "GOP” or "Democrats" were used in the headline and paired with "conservative" or "liberal" in the main body of the story. The interaction of these two elements created the cheap talk and costly talk manipulation. In a costly talk condition, for example, Conservative Ink would be blasting the documentary for its “obviously conservative politics." Where in a cheap talk condition, the same news brand would 
be criticizing liberals. Other than changing the partisan identifiers, the remainder of the text and headline was the same in both conditions. See Figure 4 for an example.

\section{Procedure}

The first step of the experiment was pre-test questions about attitudes and beliefs about news media, politics and the role of technology in society. Next, the survey software randomly assigned participants to read the non-political story on either the conservative or the liberal partisan news brand. This random assignment was done without regard to the participant's ideological view, which was not measured until the end of the survey. Once they were assigned to a news brand condition, both subsequent news stories participants read were from that same news outlet. First, participants were given a non-political story from the ideological news brand so that the perceived ideology of the news brand could be measured as a manipulation check. After this first story, credibility of the news story was measured as a manipulation check (Time $1)$.

Next, participants were shown a different news story on the same news brand. Here, the participants were randomly assigned to either the costly or cheap talk conditions, where participants read a political news story in absence of any information about how to interpret the credibility label on the screen. Credibility was again measured (Time 2). Then, participants were all given the same instructions about how to interpret the credibility label before being shown the same political news story again. These instructions read: "We're also considering a second design. This design uses an algorithm to determine the credibility of the news story on several characteristics.

o up arrows to categories where the story is found to be credible

o down arrows to categories where the story is found to be not credible. 


\section{When there are more up arrows than down arrows, the story overall is credible. When there are more down arrows than up arrows, the story overall is not credible.}

We ran the same story you just read through the algorithm. Please, take a moment to look at the story and consider the credibility arrows.” (emphasis in original).

On the screen following these instructions, participants were given a chance to read the news story again with the knowledge about how to interpret the credibility label, which indicated the story was overall not credible through a larger number of down arrows than up arrows. For the third and final time, participants again rated the credibility of the news story (Time 3). Several post-test questions were asked before participants were debriefed about the deception used in the experiment.

These symbols used in the credibility label, which are not referential to any current cues used to indicate credibility, were designed to be novel to the participants so that the stimulus could replicate conditions where an audience member encounters a heuristic cue for the first time. This allows audiences to have a chance to learn how to integrate the symbols into their credibility judgement. The labels' presence without explanation before the introduction of the instructions allow for analysis of the effect of knowing what the label indicates, not simply the presence of the symbol.

\section{Variable construction}

Ideological identity consistency. The ideological consistency variable was created by matching the news brand name participants were shown in the stimulus material with the ideology of the participant reported in the survey. The ideology of the audience and the news publication were matched, creating a folded ideological identity consistency categorical variable included inconsistent (1), consistent (2), and independents (3) (Metzger, Hartsell, \& Flanagin, 
2015). Participant ideology was measured on a scale of 1 (very liberal) to 7 (very conservative). Those who identified as very liberal, liberal, or lean liberal were grouped as liberal. Those who answered that they were moderate were in a category of independent. Those who identified as very conservative, conservative, or lean conservative were grouped as conservatives. Participant ideology was matched with the news brand with the outlet rather than the participant's political party identification because those who do not identify with a one of the major parties often still have ideological beliefs that lean one way or another. This variable, which matched the ideology of the participant with the ideology of the news brand, was used to understand the effects of processing similar or dissimilar news brands rather than the effect of the participant's political party.

Perceived message credibility. The credibility of the news story was measured on a scale from 1 (not credible) to 5 (very credible) in the same way all three times. Participants were asked to rate their perception of credibility of the story they just read based on three items from Meyer's (1988) measure: fair, unbiased and accurate. Additionally, items more recently used to measure perceived credibility were added: believable (Bucy, 2003), credible (Choi, Watt, \& Lynch, 2006) and interesting (Sundar, 1999). To capture the directionality of perceived bias, participants were asked to what extent they believed the story was biased in favor of Republicans and biased in favor of Democrats. The two elements of bias were averaged to create one factor in the overall credibility variable. Hence, all three measures of credibility were an average of six 
factors. ${ }^{2}$ The Cronbach's alphas of the six measures were .752 (Time 1); .834 (Time 2); and .816 (Time 3).

\section{Results}

\section{Manipulation checks}

Those who saw the conservative news brand condition rated the publication as more conservative than those who saw the liberal news condition, $M D=1.01, S E=.162, p<.001$. A twoway ANOVA tested the effects of the manipulations on the perceived ideology of the publication. The model significantly predicted the perceived ideology of the publication $F(3$, $349)=13.42, p=.001$. The name of the publication had a significant effect on the perceived ideology of the news brand $F(1,349)=37.56, p=.001$. There was no significant effect of the news story on perceived ideology of the news brand, $F(1,349)=1.86, p=.173$. There was no interaction $F(1,349)=.014, p=.905$. Further, participants assigned to the Liberal Ink $(N=192)$ rated the credibility $(M=2.98, S D=.83)$ on par with how those assigned to the Conservative Ink condition $(N=197)$ rated the credibility $(M=2.92, S D=.63), F(1,389)=.652, p=.42$. This confirms that random assignment worked, that the stimuli were similar enough to be compared, and that differences can be attributed to manipulations. The name of the publication had an effect on perceived ideology of the news app, while the news story did not.

Most participants correctly recalled the interpretation of the heuristic credibility cues. All participants were shown a negative credibility label, and 269 correctly recalled that the rating was negative while 107 participants incorrectly answered that it was positive. The results of the

\footnotetext{
${ }^{2}$ The exact wording of this question was: "Please rate the story you just read on the following characteristics: Believable, interesting, accurate, biased in favor of Republicans, biased in favor of Democrats, credible, fair."
} 
manipulation check are similar to the results of other experiments where audiences were asked to recall labels or credibility heuristics (Amazeen \& Muddiman, 2018; Mahone, 2014), and likely reflects the everyday, usual reading of most news audiences. For example, when participants were asked to recall if a human or machine authored the news, 218 of 573 participants (38\%) failed. This is similar to circumstances outside of experimental conditions. Indeed, a Gallup poll found that only $38 \%$ of participants could correctly recall who authored a credibility label, while a majority (56\%) said they did not recall the author (Gallup, 2019). In this experiment, an ANOVA showed no effect of the manipulated conditions on whether the participant correctly answered the manipulation check, $F(13,375)=0.9, p=.557$.

To measure to what degree ideological consistency between the news brand and the audience would affect the perceived credibility of a non-political story, I used a one-way ANOVA. The test showed no significant difference on the ideological consistency of the partisan media publication name and the participant, $F(2,386)=1.79 p=.169$. The partisan news brand name had no main effect on the perceived credibility of the non-political story.

\section{Hypotheses testing}

To test the first hypothesis, suggesting audiences will perceive costly talk between a news brand and news content as more credible than cheap talk, I analyzed the perception of credibility of the political news story that did not have a credibility label. A two-way ANOVA tested the effects of the manipulations on the perceived credibility of the story before participants were given instructions on how to interpret the credibility cues. Costly talk had a main effect on the perceived credibility $F(1,383)=4.67, p=.032$. There was no effect of the consistency of news brand name with the audience, $F(2,383)=.85, p=.427$. There was no interaction, $F(2,383)=.48$ $p=.619$. Pairwise comparisons show costly talk $(M=3.25, S E=.05)$ was perceived as more 
credible than cheap talk $(M=3.1, S E=.05)$. These results offer support for H1, suggesting that costly talk would be perceived as more credible than cheap talk. They also answer H2 by suggesting that the relationship between the audience member's personal ideology and the ideology of the news brand did not have a discernable effect on the perception of credibility of the news story overall. See Figure 1.

To test the next two hypotheses and the two research questions that ask how a negative credibility label effects the perception of credibility, I analyzed how participants' perception of credibility of the same news story changed after the negative news credibility label was introduced. I used a repeated-measure ANOVA with change in credibility as the within-subjects dependent variable and costly talk and ideological consistency as the between-subjects independent variables. The perceived credibility of the story after the negative credibility label was introduced $(M=2.75, S E=.04)$ is lower than the perceived credibility before the credibility label $(M=3.18, S E=.04), F(1,383)=106.32, p=<.001$. Answering the research questions from the same repeated-measures ANOVA, I find that costly talk $(M=3.02, S E=.04)$ was rated as more credible than cheap talk $(\mathrm{M}=2.9, \mathrm{SE}=.04), F(1,383)=4.5, p=.035$. However, I find no interaction with the consistency between news brand and audience ideology. See Table 1. Thus, while I find support for H3, there is no evidence to support H4. See Figure 2.

\section{Discussion}

This experiment was designed to understand more about how audiences process political news from partisan news brands in absence of traditional credibility heuristics. In an effort to replicate a news media environment where audiences encounter unfamiliar news brands, it tested whether credibility labels have the potential to be an effective news media literacy tool. Specifically, it looked at news brands with a specific ideological viewpoint that featured a news 
story about an ideological topic. Then, it introduced instructions on how to interpret a negative credibility label and measured how audiences updated their perception of credibility.

\section{Theoretical implications}

This study examined two layers of heuristic cues to credibility. The first layer were the ideological cues of the news brand and the news content. Past research has repeatedly shown that partisan audiences find news from ideologically similar news brands and with ideologically similar messages more credible than news from ideologically dissimilar brands or with counterattitudinal messages (Garrett, 2009; Sears \& Freedman, 1967; Westerwick, Johnson, \& Knobloch-Westerwick, 2017). When examining this layer, audiences reported that when the two ideological cues conflict - when the news brand is reporting something that goes against its ideological self-interest - audiences give the news a credibility boost. This study established that news credibility increases when a partisan news brand goes against its perceived self-interest by publishing a story that could harm the political party with which it is aligned. As predicted by the Partisan Media Opinion hypothesis (Baum \& Groeling, 2009a), audiences found the news story the most credible when the two cues were in conflict. When the news brand and the news story are from opposing viewpoints, the audience found the news story as more credible than when they are from the same viewpoint.

This suggests that the Partisan Media Opinion hypothesis can be extended to partisan news brands so that costly talk is more credible than cheap talk. This finding expands the PMO, which the authors used to explain credibility of politicians, to the credibility of ideological news sources. It suggests that audiences see ideological outlets similar to political actors, and when an ideological news brand runs a story that conflicts with its perceived self-interest it gains credibility. PMO research would suggest that is more difficult for the audience to counterargue 
this type of costly talk because it suggests that the motive is to report the truth rather than simply support the ideological team. To some degree this finding is limited in its practicality, as it seems unlikely that a news brand would run frequent stories against its ideological alignment. It also presents an interesting question for future research: Would audiences stop believing that an ideologically named news brand was authentically ideological if it consistently printed news contrary to its presumed position? In 2020, an interesting case study is emerging at The Drudge Report, which has a long reputation of favoring conservative ideology. The online news brand has for several months criticized President Donald Trump, a Republican (Norman, 2020). This research suggests that The Drudge Report would receive a credibility boost in the short term, even from fellow conservatives. But, how long will it last before audiences no longer consider The Drudge Report truly conservative?

The second layer of heuristic cues was an algorithmically produced credibility label. When the instructions on how to interpret the credibility label were followed, the audience would interpret the negative rating to mean an algorithm found the story was not credible. Across the board, the negative credibility label worked to decrease the perception of credibility of the news story. The audience overall decreased its perception of credibility about 0.3 points on a 5 -point scale. However, the results show interesting nuance: Costly talk continued to be rated higher in credibility than cheap talk. People adjust over time to new environments (Mackay \& Lowrey, 2011), and learn heuristic cues specific to an emerging news environment. These results suggest that audiences can quickly learn to integrate a credibility label into their final credibility judgement.

These results complement and expand the literature on fact-checking journalism by showing how the addition of a heuristic by an authority can help audiences find the best 
information. This study is different from fact-checking journalism research because fact-checks tend to focus on claims made by politicians. The credibility labels used here were not factchecking specific claims, but rather a news story on the whole. The results suggest that much like fact-checking journalism can nudge audiences away from misstatements of facts by people, so can credibility labels nudge audiences away from misinformation by ideological news sources. This is in line with the findings of Wood and Porter (2018), who found fact-checking journalism can nudge partisans and non-partisans away from beliefs in misinformation. However, it suggests that labels or symbols can alter the audience's perceptions of a broader unit of information: a news story rather than a single claim by a person. While fact-checking research often measures whether the fact-check changed the audience's belief in a fact (Amazeen, Thorson, Muddiman, \& Graves, 2018), this research measured how the perception of credibility was changed. Here, audiences adjusted their perception of credibility based on the authority of the credibility label. The interaction between the ideological news sources and the news content also continued to have an effect. That all these types of information are accounted for in the final credibility judgement suggests more complex processing.

\section{Practical implications}

These circumstances of this experiment, which require learning how to interpret heuristic cues to credibility, reflect when a technology advancement in news delivery technology changes the heuristic cues available to the audience. For example, online news introduced a multitude of previously unknown news brands and indicators of social recommendations that continue to evolve today. The main findings of this study offer evidence that news credibility labels will be effective as a news media literacy tool - even in partisan contexts. These findings have implications for theories of news information processing in the evolving genre of partisan- 
branded news, and can be useful for organizations like Facebook, Google News and NewsGuard that are interested in implementing credibility labels. These results suggest that news credibility labels for unfamiliar news brands will do no harm, and have the potential to nudge audiences toward media literacy.

Further, the complexity of audience credibility judgments suggests that audiences are willing to engage with various cues to credibility to make a final judgment. While media critics chastise audiences for being lazy or only relying on their preferred sources and confirmation bias, these findings instead suggest the audience is adapting. Audiences are by necessity cognitive misers, but these results should give hope that audiences are willing to put in the effort to assess multiple cognitive cues and develop media literacy skills.

\section{Limitations}

While encouraging, the effectiveness of credibility labels in this finding is caveated by two important limitations. In this one-shot experiment, participants lacked the long-term exposure to the news brand that they have with cable news networks that might cause the audience to interpret the content with additional perceived bias. The effects observed in this this experiment were much more closely aligned to what may be observed when an online news reader stumbles across a news story on an unfamiliar website through a search engine like Google or a social networking platform like Facebook.

The findings regarding the political story are limited by the design of the experiment, which exposed all participants to the news story first and the credibility label second. Because of this, these analyses cannot be extended to credibility labels that are displayed simultaneously to the first exposure to a news brand. Because credibility information is most effective when given 
to audiences before they read the story (Duncan, 2019), the procedures used here may not show the full potential of a credibility label shown to audiences in different orders.

These decisions also introduce order effects and demand effects that limit the generalizability of the findings. Though deception was used, audiences may have felt some expectation that they were to reduce their perception of credibility. While measuring perception of credibility twice allowed me to measure changes in credibility, these results cannot isolate to what degree participants would change their perception of credibility if they were not asked to rate their perception of credibility twice. By asking twice, participants may have felt pressure to change their rating. The limited scope of this study did not test the efficacy of a positive credibility label, and participants may respond differently to a label that indicates the story is credible. Participants all read a news story that was non-political as a manipulation check that the news brand was perceived as partisan. However, this choice means that people who did not see the same sequence of stimulus may report differing effects.

\section{Future research}

To address these limitations, future research could explore different credibility label systems, including specifically those proposed by news and technology companies. Further, it could measure the effectiveness of the credibility labels on different stories, including nonpolitical stories. The limitations of this experiment introduced by using unfamiliar partisan news brands suggest that future researchers should use survey research to understand how the Partisan Media Opinion hypothesis and credibility labels operate on more familiar news brands. The news brands used here and actual news brands with partisan reputations such as CNN and Fox News Channel have three major differences: First, CNN and Fox News are familiar to the audience, are generally reporting truthful news and claim that their news reporting is non-partisan. For these 
reasons, the way credibility labels operate on more familiar news brands and news brands that are not explicitly partisan may operate differently.

Additionally, should credibility labels be deployed on a large scale they would be seen by a much larger number of people than the number of participants used in this experiment. As the cottage industry of credibility labels expands, possibly millions would be exposed to the heuristic cues. This could mean that even very small effects sizes could have massive implications to large populations. More and larger-scale research should investigate the effects of credibility labels to determine how audiences interact in circumstances where the issues are more salient and the typical social sharing and commenting mechanisms are available to audiences.

\section{Conclusion}

Each time technology upends what news audiences know about interpreting heuristic credibility cues, audiences become vulnerable to those who may take advantage of the temptation to believe misinformtion. Yet studying those moments in transitions between major news platform revolutions is difficult because it's nearly impossible to predict the next television, internet or Facebook. This study used the emergence of news apps as an opportunity to begin exploring the potential effectiveness of credibility labels as a news media literacy tool to help audiences' transition through those technology changes. It contributes to the literature by expanding the Partisan Media Opinion hypothesis to partisan news brands and finds a mismatch between the ideological perspectives of a news story and the news brand is rated as more credible than when the perspectives match. This suggests that credibility labels can be an effective news media literacy tool as audiences navigate a world with hundreds of partisan news brands. 


\section{References}

Amazeen, M. A., \& Muddiman, A. R. (2018). Saving media or trading on trust? The effects of native advertising on audience perceptions of legacy and online news publishers. Digital journalism, 6(2), 176-195.

Amazeen, M. A., Thorson, E., Muddiman, A., \& Graves, L. (2018). Correcting political and consumer misperceptions: The effectiveness and effects of rating scale versus contextual correction formats. Journalism \& Mass Communication Quarterly, 95(1), 28-48.

Ansolabehere, S., \& Iyengar, S. (1996). Can the press monitor campaign advertising? An experimental study. Harvard International Journal of Press/Politics, 1(1), 72-86.

Ariyanto, A., Hornsey, M. J., \& Gallois, C. (2007). Group allegiances and perceptions of media bias: Taking into account both the perceiver and the source. Group Processes \& Intergroup Relations, 10(2), 266-279.

Armstrong, C. L., \& McAdams, M. J. (2009). Blogs of information: How gender cues and individual motivations influence perceptions of credibility. Journal of ComputerMediated Communication, 14(3), 435-456.

Baum, M. A., \& Groeling, T. (2008). New media and the polarization of American political discourse. Political Communication, 25(4), 345-365.

Baum, M. A., \& Groeling, T. (2009b). Shot by the messenger: Partisan cues and public opinion regarding national security and war. Political Behavior, 31(2), 157-186. doi: 10.1007/s11109-008-9074-9.

Baum, M. A., \& Groeling, T. J. (2009a). War stories: The causes and consequences of public views of war. Princeton University Press. 
Baum, M. A., \& Gussin, P. (2008). In the eye of the beholder: How information shortcuts shape individual perceptions of bias in the media. Quarterly Journal of political science, 3(1), $1-31$.

Bergen, M. (2017). Google brings fake news fact checking to search results. Bloomberg News. https://www.bloomberg.com/news/articles/2017-04-07/google-brings-fake-news-factchecking-to-search-results.

Bucy, E. P. (2003). Media credibility reconsidered: Synergy effects between on-air and online news. Journalism \& Mass Communication Quarterly, 80(2), 247-264.

Bucy, E. P. (2004). The interactivity paradox: Closer to the news but confused. Media access: Social and psychological dimensions of new technology use, 47-72.

Bullock, J., Gerber, A., Hill, S., and Huber, G. (2015), "Partisan Bias in Factual Beliefs about Politics," Quarterly Journal of Political Science: Vol. 10: No. 4, pp 519-578. doi: $10.1561 / 100.00014074$

Burbules, N. C. (1998). Rhetorics of the Web: Hyperreading and critical literacy. Page to screen: Taking literacy into the electronic era, 102, 122.

Cappella, J. N., \& Jamieson, K. H. (1994). Broadcast adwatch effects: A field experiment. Communication Research, 21(3), 342-365.

Chaiken, S. (1980). Heuristic versus systematic information processing and the use of source versus message cues in persuasion. Journal of personality and social psychology, 39(5), 752. doi: $10.1037 / 0022-3514.39 .5 .752$.

Chaiken, S., \& Maheswaran, D. (1994). Heuristic processing can bias systematic processing: effects of source credibility, argument ambiguity, and task importance on attitude judgment. Journal of personality and social psychology, 66(3), 460. 
Choi, J. H., Watt, J. H., \& Lynch, M. (2006). Perceptions of news credibility about the war in Iraq: Why war opponents perceived the Internet as the most credible medium. Journal of computer-mediated communication, 12(1), 209-229.

Coe, K., Tewksbury, D., Bond, B. J., Drogos, K. L., Porter, R. W., Yahn, A., \& Zhang, Y. (2008). Hostile news: Partisan use and perceptions of cable news programming. Journal of Communication, 58(2), 201-219. doi: 10.1111/j.1460-2466.2008.00381.x

Diakopoulos, N. (2019). Automating the News: How Algorithms Are Rewriting the Media. Harvard University Press.

Duncan, M. (2019). The effectiveness of credibility indicator interventions in a partisan context. Newspaper Research Journal, 0739532919873707.

Farhi, P. (2018). “A journalistic fix for fake news? A new venture seeks to take on the epidemic.” Washington Post. Retrieved from: https://www.washingtonpost.com/lifestyle/style/a-journalistic-fix-for-fake-news-a-newventure-seeks-to-take-on-the-epidemic/2018/03/02/065438ca-1daf-11e8-b2d908e748f892c0_story.html?utm_term=.62adb7692719.

Festinger, L. (1957). A theory of cognitive dissonance. Stanford, CA: Stanford University Press.

Fiske, S.T., \& Taylor, S.E. (1991). Social Cognition (2nd ed.). New York: McGraw-Hill.

Flanagin, A. J., \& Metzger, M. J. (2000). Perceptions of Internet information credibility. Journalism \& Mass Communication Quarterly, 77(3), 515-540.

Garrett, R. K. (2009). Politically motivated reinforcement seeking: Reframing the selective exposure debate. Journal of Communication, 59(4), 676-699. doi: 10.1111/j.14602466.2009.01452.x. 
Garrett, R. K., Carnahan, D., \& Lynch, E. K. (2013). A turn toward avoidance? Selective exposure to online political information, 2004-2008. Political Behavior, 35(1), 113-134. doi: 0.1007/s11109-011-9185-6.

Go, E., Jung, E. H., \& Wu, M. (2014). The effects of source cues on online news perception. Computers in Human Behavior, 38, 358-367. doi: 10.1016/j.chb.2014.05.044.

Graves, L. (2016). Deciding what's true: The rise of political fact-checking in American journalism. Columbia University Press.

Graves, L., \& Glaisyer, T. (2012). The fact-checking universe in Spring 2012. New America. Gunther, A. (1988). Attitude extremity and trust in media. Journalism Quarterly, 65(2), 279-287. Iyengar, S., \& Hahn, K. S. (2009). Red media, blue media: Evidence of ideological selectivity in media use. Journal of Communication, 59(1), 19-39. doi: 10.1111/j.14602466.2008.01402.x.

Jerkowitz, M., Mitchell, A., Shearer, E., \& Walker, M. (2020). U.S. media polarization and the 2020 Election: A nation divided. Pew Research Center. https://www.journalism.org/wpcontent/uploads/sites/8/2020/01/PJ_2020.01.24_Media-Polarization_FINAL.pdf

Johnson, T. J., \& Kaye, B. K. (2014). Credibility of social network sites for political information among politically interested internet users. Journal of Computer-mediated communication, 19(4), 957-974.

Jung, J., Song, H., Kim, Y., Im, H., \& Oh, S. (2017). Intrusion of software robots into journalism: The public's and journalists' perceptions of news written by algorithms and human journalists. Computers in human behavior, 71, 291-298.

Katz, E., Blumler, J. G., \& Gurevitch, M. (1974). The uses of mass communications: Current perspectives on gratifications research (p. 19). Thousand Oaks, CA: Sage publications. 
Kohring, M., \& Matthes, J. (2007). Trust in news media: Development and validation of a multidimensional scale. Communication research, 34(2), 231-252.

Lewandowsky, S., Ecker, U. K., \& Cook, J. (2017). Beyond Misinformation: Understanding and Coping with the "Post-Truth" Era. Journal of Applied Research in Memory and Cognition, 6(4), 353-369. doi: 10.1016/j.jarmac.2017.07.008.

Liu, Z. (2004). Perceptions of credibility of scholarly information on the web. Information Processing \& Management, 40(6), 1027-1038.

Liu, B., \& Wei, L. (2019). Machine Authorship In Situ: Effect of news organization and news genre on news credibility. Digital Journalism, 7(5), 635-657.

Mackay, J. B., \& Lowrey, W. (2011). The credibility divide: reader trust of online newspapers and blogs. Journal of Media Sociology, 3(1-4), 39-57.

McCroskey, J. C., \& Young, T. J. (1981). Ethos and credibility: The construct and its measurement after three decades. Communication Studies, 32(1), 24-34.

Mahone, J. A. (2014). Attribution has little effect on perceived credibility. Newspaper Research Journal, 35(1), 108-122.

Marsh, E. J., \& Yang, B. W. (2017). A Call to Think Broadly about Information Literacy. Journal of Applied Research in Memory and Cognition, 6(4), 401-404. DOI: /10.1016/j.jarmac.2017.09.012

Metzger, M. J., Flanagin, A. J., Eyal, K., Lemus, D. R., \& McCann, R. M. (2003). Credibility for the 21 st century: Integrating perspectives on source, message, and media credibility in the contemporary media environment. Annals of the International Communication Association, 27(1), 293-335. doi: 10.1080/23808985.2003.11679029. 
Metzger, M. J., Hartsell, E. H., \& Flanagin, A. J. (2015). Cognitive dissonance or credibility? A comparison of two theoretical explanations for selective exposure to partisan news. Communication Research. doi: 0093650215613136.

Meyer, P. (1988). Defining and measuring credibility of newspapers: Developing an index. Journalism quarterly, 65(3), 567-574.

Newell, S. J., \& Goldsmith, R. E. (2001). The development of a scale to measure perceived corporate credibility. Journal of Business Research, 52(3), 235-247.

Norman, B. (2020). Why did Matt Drudge turn on Trump? Columbia Journalism Review. https://www.cjr.org/politics/drudge-report-trump.php

Nyhan, B., \& Reifler, J. (2010). When corrections fail: The persistence of political misperceptions. Political Behavior, 32(2), 303-330. doi: 10.1007/s11109-010-9112-2.

O'Sullivan, P. B., \& Geiger, S. (1995). Does the watchdog bite? Newspaper ad watch articles and political attack ads. Journalism \& Mass Communication Quarterly, 72(4), 771-785.

Ormus, W. (2019) “Just trust us: In an era of fake news, a cottage industry of is competing to turn media credibility into a booming business." Slate. https://slate.com/technology/2019/01/newsguard-nuzzelrank-media-ratings-fake$\underline{\text { news.html }}$

Pennycook, G. \& Rand, D. G. (2017). Assessing the Effect of 'Disputed' Warnings and Source Salience on Perceptions of Fake News Accuracy. Retrieved from: https://ssrn.com/abstract=3035384.

Porter, E., \& Wood, T. J. (2019). False Alarm: The Truth About Political Mistruths in the Trump Era. Cambridge University Press. 
Prasad, M., Perrin, A. J., Bezila, K., Hoffman, S. G., Kindleberger, K., Manturuk, K., \& Powers, A. S. (2009). "There must be a reason": Osama, Saddam, and inferred justification. Sociological Inquiry, 79(2), 142-162. doi: 10.1111/j.1475-682X.2009.00280.x

Schaffner, B. F., \& Roche, C. (2016). Misinformation and motivated reasoning: Responses to economic news in a politicized environment. Public Opinion Quarterly, 81(1), 86-110. doi: $10.1093 / \mathrm{poq} / \mathrm{nfw} 043$

Sears, D. O., \& Freedman, J. L. (1967). Selective exposure to information: A critical review. Public Opinion Quarterly, 31(2), 194-213.

Silverman, C. (2017). Facebook wants to teach you how to spot fake news. BuzzFeed News. Retrieved from: https://www.buzzfeed.com/craigsilverman/facebook-wants-to-teach-youhow-to-spot-fake-news-on?utm term=.qcwJz9Kvg\#.inZAVwygd.

Silverman, C., Lytvyneko, J., Vo, L.T., \& Singer-Vine, J. (2017). "Inside the partisan fight for your news feed.” BuzzFeed News. Retrieved from: https://www.buzzfeed.com/craigsilverman/inside-the-partisan-fight-for-your-news-feed.

Stroud, N. J. (2008). Media use and political predispositions: Revisiting the concept of selective exposure. Political Behavior, 30(3), 341-366. doi: 10.1007/s11109-007-9050-9.

Stroud, N. J. (2010). Polarization and partisan selective exposure. Journal of Communication, 60(3), 556-576.

Stroud, N. J., \& Lee, J. K. (2013). Perceptions of cable news credibility. Mass Communication and Society, 16(1), 67-88. doi: 10.1080/15205436.2011.646449.

Sundar, S. S. (2008). The MAIN model: A heuristic approach to understanding technology effects on credibility. Digital media, youth, and credibility, 73100. doi: 10.1162/dmal.9780262562324.073. 
Sundar, S. S. (1999). Exploring receivers' criteria for perception of print and online news. Journalism \& Mass Communication Quarterly, 76(2), 373-386.

Sundar, S. S., Knobloch-Westerwick, S., \& Hastall, M. R. (2007). News cues: Information scent and cognitive heuristics. Journal of the Association for Information Science and Technology, 58(3), 366-378. 10.1002/asi.20511.

Taber, C. S., \& Lodge, M. (2006). Motivated skepticism in the evaluation of political beliefs. American Journal of Political Science, 50(3), 755-769. doi: 10.1111/j.15405907.2006.00214.x.

Thorson, E. (2016). Belief echoes: The persistent effects of corrected misinformation. Political Communication, 33(3), 460-480.

Tsfati, Y., \& Cappella, J. N. (2003). Do people watch what they do not trust? Exploring the association between news media skepticism and exposure. Communication Research, 30(5), 504-529.

Turner, J. (2007). The messenger overwhelming the message: Ideological cues and perceptions of bias in television news. Political Behavior, 29(4), 441-464.

Waddell, T. F. (2019). Can an Algorithm Reduce the Perceived Bias of News? Testing the Effect of Machine Attribution on News Readers' Evaluations of Bias, Anthropomorphism, and Credibility. Journalism \& Mass Communication Quarterly, 96(1), 82-100.

Westerwick, A., Johnson, B. K., \& Knobloch-Westerwick, S. (2017). Confirmation biases in selective exposure to political online information: Source bias vs. content bias. Communication Monographs, 84(3), 343-364.

Wood, T., \& Porter, E. (2018). The elusive backfire effect: mass attitudes' steadfast factual adherence. Political Behavior, 1-29. doi: 10.1007/s11109-018-9443-y 
Xu, Q. (2013). Social recommendation, source credibility, and recency: Effects of news cues in a social bookmarking website. Journalism \& Mass Communication Quarterly, 90(4), 757775. doi: $10.1177 / 1077699013503158$.

Young, D. G., Jamieson, K. H., Poulsen, S., \& Goldring, A. (2017). Fact-Checking Effectiveness as a Function of Format and Tone: Evaluating FactCheck. org and FlackCheck. org. Journalism \& Mass Communication Quarterly. doi: 1077699017710453. 


\section{Figures}

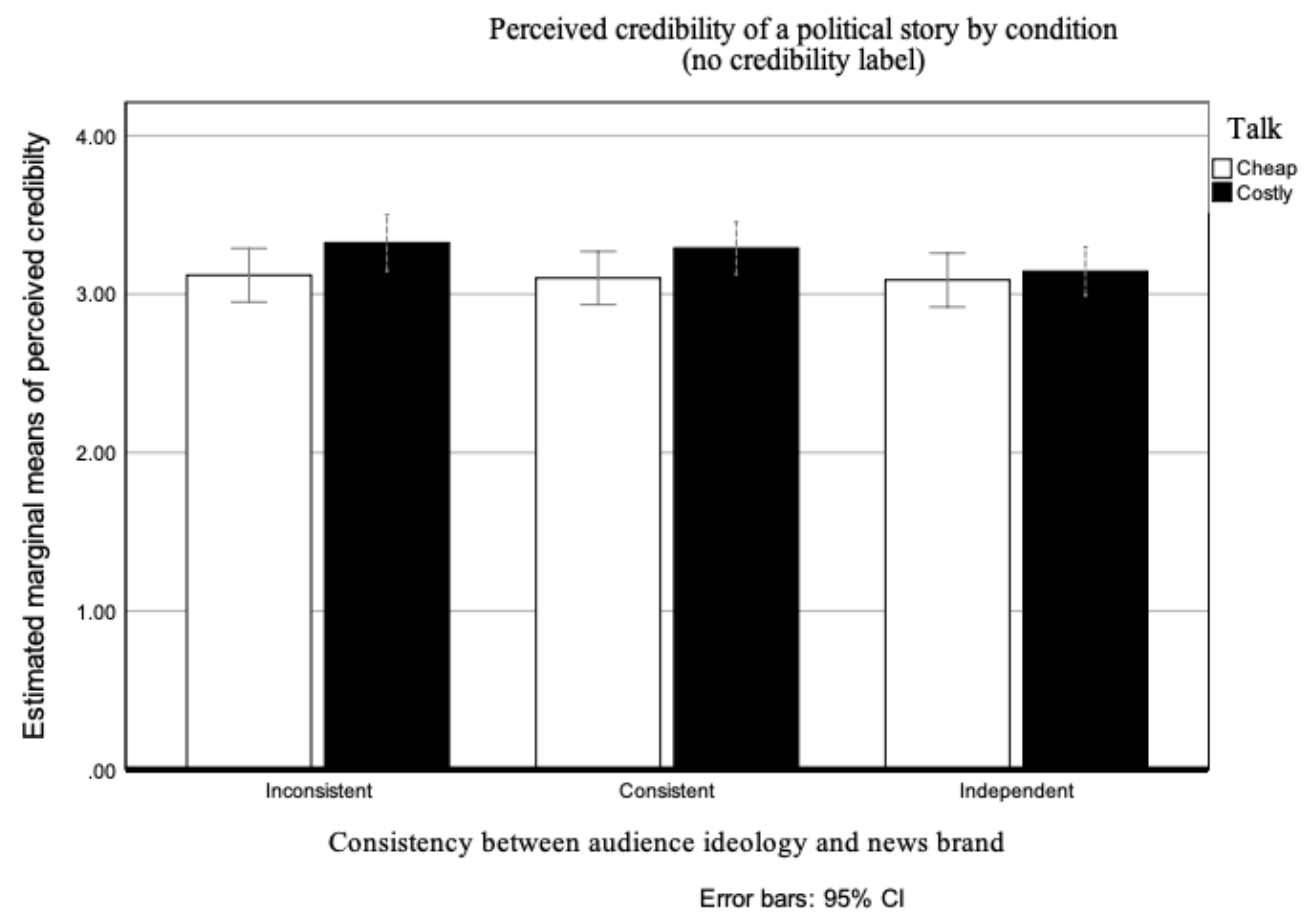

Figure 1: Perceived credibility of a political story by condition without a credibility label. The costly talk news story, where the news story conflicted with the news brand, was perceived as more credible than cheap talk. There was no effect of the interaction between the news brand and the audience ideology. 




Figure 2: Change in perceived credibility in the costly talk condition after a negative credibility label. There was a main effect of the credibility label that decreased the perception of credibility. 


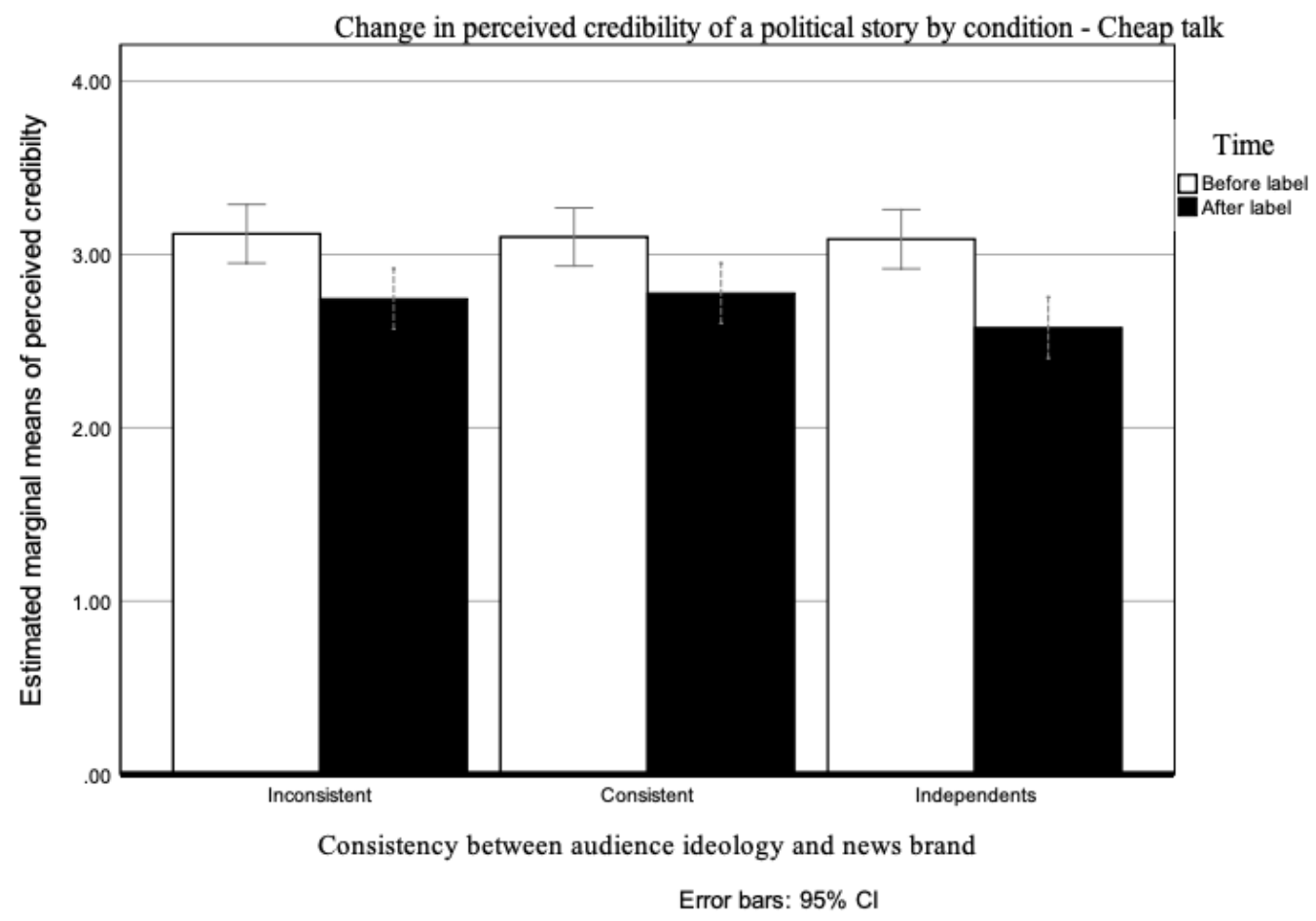

Figure 3: Change in perceived credibility in the cheap talk condition after a negative credibility label. There was a main effect of the credibility label that decreased the perception of credibility. Further, costly talk continued to be more rated as more credible than cheap talk. 


\section{The liberal politics of webseries getting extra scrutiny}

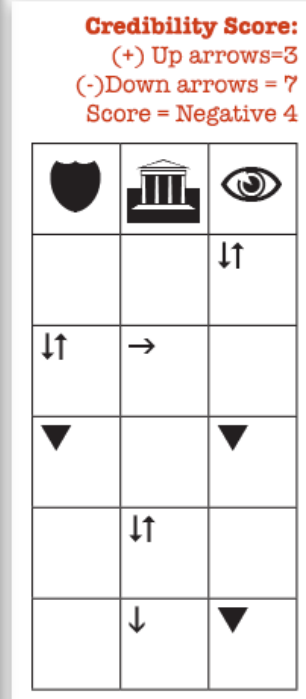

A new webseries on county-level prosecutors is getting extra scrutiny for its obvious liberal
politics.

The webserles was produced during the past three years by going behind the curtain of America's most secret court proces for "The Grand Jury.

The series, which has not been put online for the

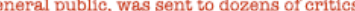
ncluding those at Conservative Ink, as a preview. Many of those critics are now saying the content of the series shouldn't be taken at face value because the filmmakers were using selective editing and had a clear agenda: Smear the prosecutors an protecting law enforcement at all costs.

After a number of grand juries failed to return charges on police officers who wrere involved in the arrests of suspects, the film makers said they felt the role of the grand jury was misunderstood.

For several years, Max Barnada and All Redman used various tactios to get an inside look at prosecutorial meetings and grand jury proceedings.

While Barnada and Redman present the story as unbiased, truthful account of grand juries, prominent conservative prosecutors are sayin the editing is unethical and that the film makers misrepresent justioe.

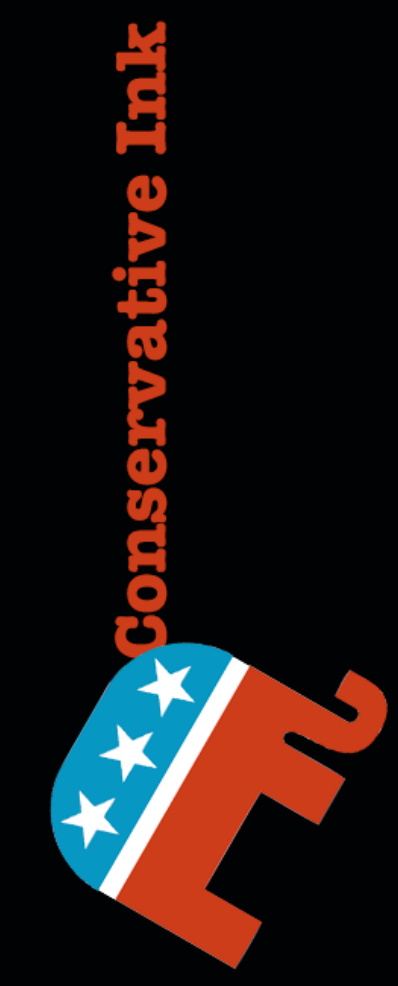

Figure 4. Stimulus example - Conservative Ink, cheap talk, with credibility label (Time 3) 
Tables

Table 1

Effect of ideological consistency and talk on the change in perceived credibility after the introduction of the credibility label.

\begin{tabular}{lllll}
\hline & $\boldsymbol{d} \boldsymbol{f}$ & Mean Square & $\boldsymbol{F}$ & $\boldsymbol{p}$ \\
\hline Intercept & 1 & 6764.28 & 10795 & $>.001$ \\
Talk & 1 & 2.82 & 4.5 & .035 \\
Ideological consistency & 2 & 1.79 & 2.85 & .059 \\
Interaction term & 2 & .14 & .22 & .799 \\
Error & 383 & .63 & & \\
\hline
\end{tabular}

